\title{
PENERAPAN BAHAN AJAR MATEMATIKA BERBASIS REALISTIC MATHEMATICS EDUCATION (RME) TERHADAP KEMAMPUAN PEMECAHAN MASALAH MATEMATIS SISWA
}

\author{
${ }^{1}$ Salma Aprianka \\ ${ }^{1}$ Pendidikan Matematika, Fakultas Keguruan dan Ilmu Pendidikan Universitas Muhammadiyah Sukabumi \\ salmaaprianka25@gmail.com
}

\begin{abstract}
Abstrak
Penelitian ini dilakukan untuk mengkaji penggunaan bahan ajar matematika berbasis Realistic Mathematics Education (RME) terhadap kemampuan pemecahan masalah matematis siswa. Penelitian ini menggunakan metode penelitian kualitatif dengan jenis kepustakaan. Metode penelitian yang digunakan dalam pengumpulan data melalui literature, buku, jurnal dan lain sebagainya, sehingga tidak mengharuskan peneliti untuk terjun kelapangan secara langsung. Hasil yang diperoleh dari penelitian ini adalah penerapan bahan ajar matematika yang berbasis Realistic Mathematics Education (RME) diharapkan dapat menunjukan pengaruh yang baik terhadap kemampuan pemecahan masalah matematis siswa. Terdapat faktor yang mempengaruhi hal tersebut diantaranya 1) di dalam bahan ajar terdapat permasalah konstektual, 2) siswa lebih termotivasi karena berkaitan dengan kehidupan sehari-hari.
\end{abstract}

Kata kunci : Realistic Mathematics Education (RME), bahan ajar matematika berbasis Realistic Mathematics Education (RME), kemampuan pemecahan masalah.

\section{PENDAHULUAN}

Matematika merupakan ilmu pengetahuan yang dibentuk dari hasil pemikiran manusia dan berhubungan dengan ide,proses dan penalaran (Kusumawardani, dkk : 2018). Matematika memiliki karakteristik yaitu memiliki objek yang abstrak, berhubungan dengan nalar atau logika, dan dapat dialihgunakan terhadap ilmu pengetahuan yanglain maupun dalam kehidupan sehari-hari. Matematika juga berperan dalam pembentukan kemampuan matematis siswa salah satunya kemampuan pemecahan masalah baik secara teoritis maupun dalam kehidupan sehari - hari . Oleh sebab itu matematika sangat penting dipelajari untuk semua jenjang pendidikan dari dasar sampai pendidikan tinggi.

Matematika memiliki peranan penting terhadap kemajuan ilmu pengetahuan dan teknologi, oleh karena itu siswa diharapkan setelah mempelajari matematika akan lebih siap untuk menghadapi perkembangan yang akan terjadi nantinya. Selain itu siswa diharapkan memiliki kemampuan pemecahan masalah matematis baik secara teoritis maupun dalam kehidupan sehari hari. Pengembangan kemampuan pemecahan masalah ini tidak hanya bertumpu pada siswa itu sendiri melainkan ada faktor lain yang menunjang peningkatan kemampuan ini, salah satunya guru dan bahan ajar. Guru diharapkan dapat memberikan materi dan contoh soal yang berkaitan dengan kehidupan seharihari sehingga dapat meningkatkan kemampuan pemecahan masalah matematis siswa. Bahan ajar dijadikan fasilitator untuk mempermudah dan membantu meningkatkan kemampuan siswa terutama pemacahan masalah baik secara teoritis maupun dalam kehidupan sehari-hari.

Namun kenyataan di lapangan menyatakan fakta bahwa masih rendahnya tingkat kemampuan pemecahan masalah matematis siswa dilihat dari hasil tes yang diselenggarakan oleh Programme for Internasional Student Assessment (PISA) yang diselenggarakan oleh Organization for Economic Co-operation and Development (OECD) pada tahun 2015, rata-rata nilai siswa Indonesia adalah 386 dan menempati peringkat ke62 dari 69 negara peserta. Hal ini juga didukung oleh hasil keikutsertaan Indonesia dalam Treads in International Matematics and Science Study (TIMSS) (Haryanti, 2015:2-3) mengatakan bahwa, salah satu indikator yang dinilai dalam TIMSS Nilai standar ratarata yang ditetapkan oleh TIMSS adalah 500. Dalam empat kali keikutsertaan, Indonesia masih ada di peringkat bawah. 
Hal ini dipengaruhi oleh beberapa faktor yaitu (1) metode yang digunakan adalah metode lama yaitu metode ceramah (2) kurang aktif dan kurang antusias dalam proses belajar mengajar (3) rendahnya tingkat kemampuan pemecahan masalah (4) proses belajar masih terpaku kepada guru (5) belum ada bahan ajar yang menunjang untuk meningkatkan kemampuan pemecahan masalah matematis siswa. Oleh karenanya diperlukan adanya bahan ajar yang menunjang untuk meningkatkan kemampuan pemecahan masalah matematis siswa.

Bahan ajar yang digunakan selayaknya dapat membantu guru maupun siswa untuk mencapai tujuan pembelajaran salah satunya dapat meningkatkan kemampuan pemecahan masalah matematis siswa tidak hanya secara teoritis tetapi juga dalam kehidupan sehari - hari. Pemecahan masalah merupakan salah satu tujuan dalam proses pembelajaran ditinjau dari aspek kurikulum. Pentingnya pemecahan masalah dalam pembelajaran juga disampaikan oleh National Council of Teacher of Mathematics (NCTM). NCTM (2000) proses berfikir matematika dalam pembelajaran matematika meliputi lima kompetensi standar utama yaitu kemampuan pemecahan masalah, kemampuan penalaran, kemampuan koneksi, kemampuan komunikasi dan kemampuan representasi. Rendahnya kemampuan ini akan berakibat pada rendahnya kualitas sumber daya manusia, yang ditunjukkan dalam rendahnya kemampuan pemecahan masalah(Muhammad Daut Siagian, (2016)). Realistic Mathematics Education (RME) merupakan pendekatan yang menekankan pada konseptualisasi pengajaran dan memiliki kecenderungan peserta didik menjadi peserta aktif dalam proses belajar mengajar (Afriansyah, E. A. (2016)). Dalam teori Realistic Mathematics Education (RME), instruksional matematika didasarkan pada persoalan praktis dalam konteks kehidupan sehari-hari sehingga matematika selalu menjadi bermakna bagi peserta didik. oleh karena itu diperlukan bahan ajar matematika berbasis Realistic Mathematics

Education (RME) agar dapat meningkatkan kemampuan pemecahan masalah matematis siswa. Tujuan dari penelitian ini adalah untuk melihat efektifitas penggunaan bahan ajar matematika berbasis Realistic Mathematics Education (RME) untuk meningkatkan kemampuan pemecahan masalah matematis siswa.

\section{METODE PENELITIAN}

Metode yang digunakan dalam penelitian ini adalah metode kualitatif dengan jenis studi kepustakaan. Penelitian kepustakaan merupakan metode penelitian yang digunakan dalam pengumpulan data melalui literature,buku,jurnal dan lain sebagainya dan metode ini tidak mengharuskan peneliti untuk terjun kelapangan secara langsung.

\section{HASIL DAN PEMBAHASAN}

Bahan ajar matematika berbasis Realistic Mathematics Education (RME) ini berisi materi pembelajaran dan latihan soal yang dikaitkan ke dalam kehidupan sehari - hari. Adapun tujuannya untuk meningkatkan kemapuan pemecahan masalah siswa dan memberikan pembelajaran yang berarti untuk siswa. Amin menyatakan bahwa bahan ajar matematika harus sesuai dengan kurikulum, menggunakan masalah realistik untuk memotivasi dan membantu siswa belajar, menjalin konsep matematika dari domain yang berbeda untuk memberikan kesempatan siswa belajar bermakna dan matematika terpadu, memiliki bahan pengayaan untuk mengakomodasi berbagai cara dan tingkat pemikiran siswa, dan mampu mendorong siswa untuk berpikir kritis, kreatif, inovatif, dan merangsang interaksi dan kerjasama siswa (Mochamad Farid Ubaidillah, dkk,2017). Oleh karena itu, diperlukan bahan ajar berbasis Realistic Mathematics Education (RME) agar ketersediaan bahan ajar sesuai dengan kebutuhan siswa, tuntutan kurikulum, karakteristik sasaran, dan tuntutan pemecahan masalah belajar. 


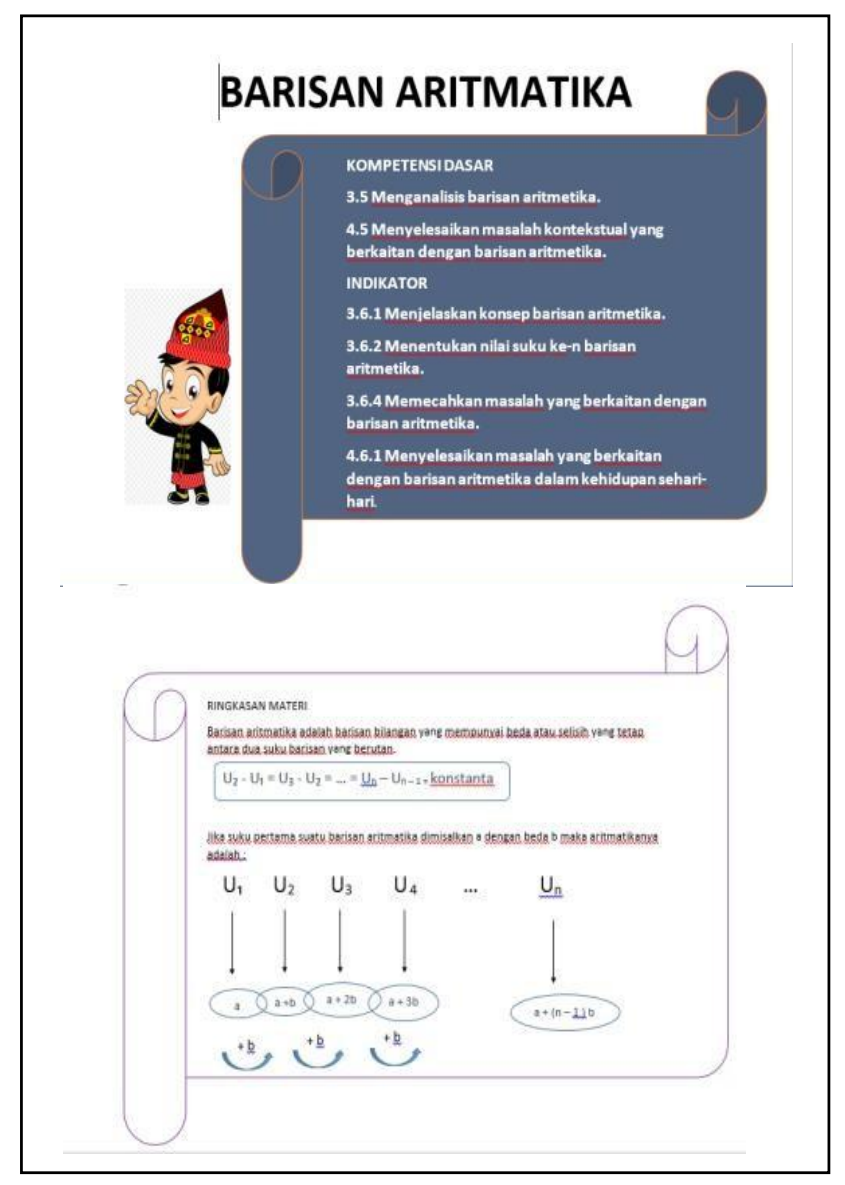

Gambar 1 layout bahan ajar

Dari gambar di atas dapat dilihat bahan ajar berbasis Realistic Mathematics Education (RME) berisi materi barisan aritmatika yang menjabarkan asal dari rumus baku barisan aritmatika. Bahan ajar di atas mengajarkan siswa untuk dapat berpikir secara sistematis, dapat memecahkan masalah dari asal muasal rumus baku barisan aritmatika dan akhirnya dapat menyimpulkan akhir dari rumus baku tersebut. Pengajaran tersebut berdasarkan dengan karakteristik pembelajaran matematika berbasis Realistic Mathematics Education (RME). Selain pengenalan materi, di dalam bahan ajar juga diberikan permasalahan matematika yang berkaitan dengan permasalah di dalam kehidupan sehari - hari seperti berikut.

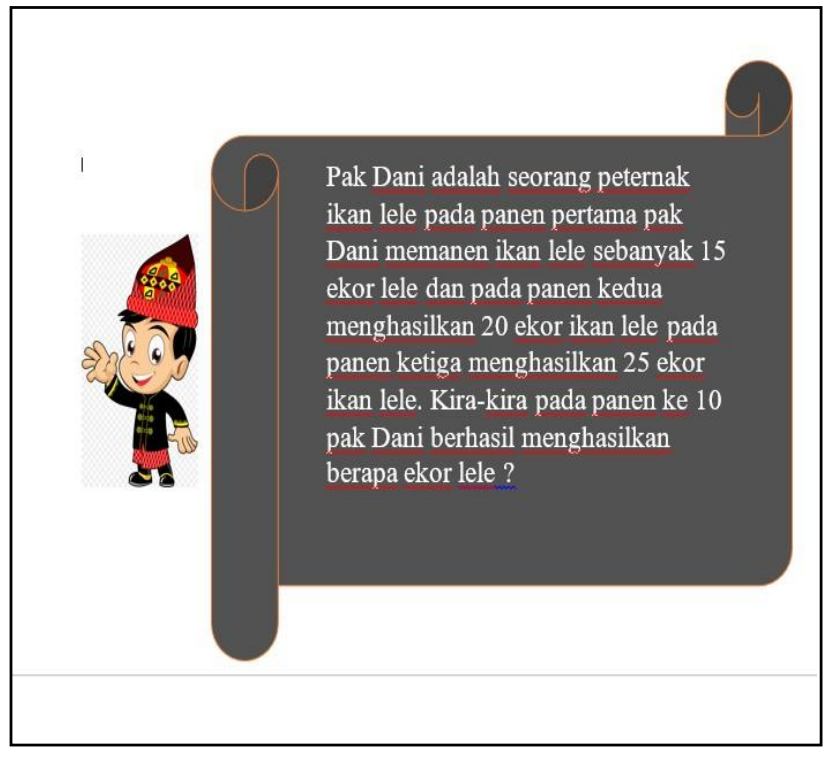

Gambar 2 contoh permasalahan

Adanya contoh permasalah di dalam bahan ajar yang berkaitan dengan permasalahan dalam kehidupan sehari - hari itu bertujuan untuk melatih siswa agar terbiasa dengan pola soal pemecahan masalah. Dalam bahan ajar ini juga memberikan permasalahan yang membutuhkan langkah - langkah model pemecahan masalah yang juga sejalan dengan karakteristik dan juga prinsip model pembelajaran Realistic Mathematics Education (RME) yaitu siswa diberikan kesempatan untuk memberikan ide atau gagasan untuk model matematika seperti diketahui,yang ditanyakan, dan kelengkapan soal.selanjutnya siswa dituntut untuk memecahkan masalah yang ada pada soal dan dikaitkan dengan kehidupan sehari - hari siswa juga bisa membuat cara sendiri untuk memecahkan masalah yang diberikan dan dibandingkan dengan rumus baku yang sudah ada. Yang terakhir siswa menyimpulkan hasil daripengerjaan latihan soal yang sudah diberikan. Lalu siswa mampu menjelaskan atau memaparkan hasil kerjanya dan dapat mengoreksi hasilnya meliputi kebenaran penghitungan,kebenaran rumus, dan kesalahan dalam pengerjaan.

Bahan ajar ini juga mengharuskan siswa untuk menemukan solusi atau pemecahan masalah dari latihan soal yang diberikan. Siswa juga dituntut dapat menganalisis soal dan mengkonstruksi sendiri pengetahuan dengan cara latihan soal cerita yang berkaitan dengan kehidupan sehari - hari juga menentukan rumus. 


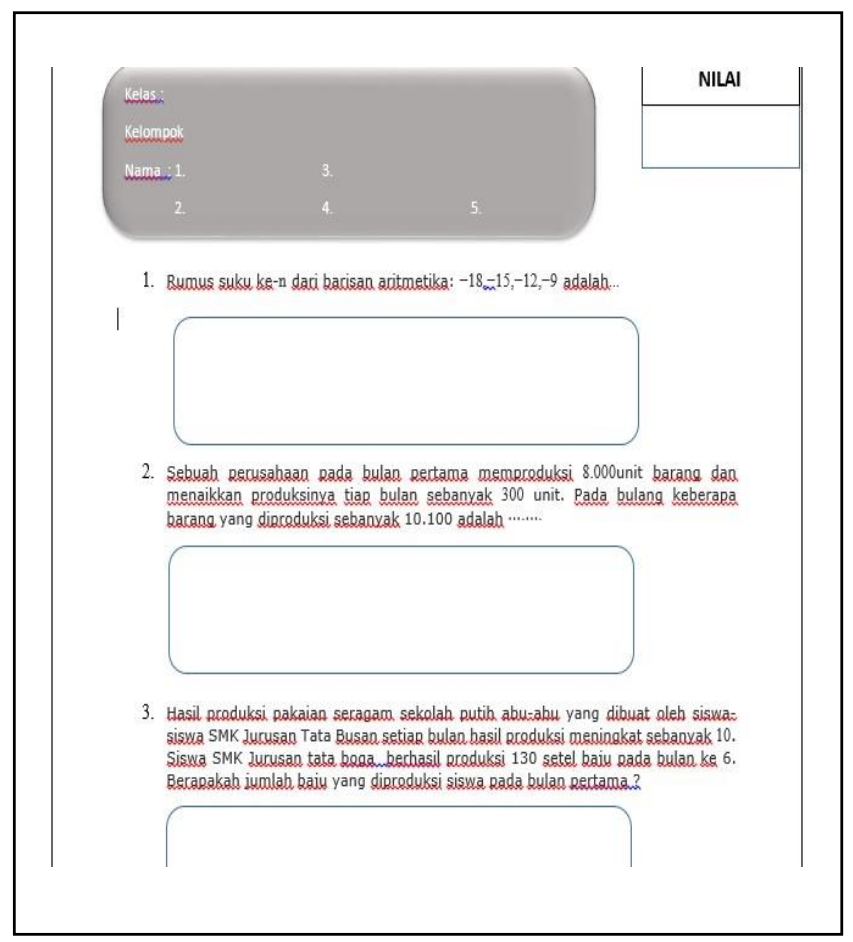

Gambar 3 Lembar Kerja Siswa

Dengan pembelajaran dan bahan ajar ini diharapkan siswa dapat meningkatkan motivasi belajar dan kemampuan pemecahan masalah siswa. Hal ini dikarenakan di dalam bahan ajar berbasis Realistic Mathematics Education (RME) ini selain siswa belajar materi matematika secara teoritis tapi juga sesuai dengan permasalahan yang ada dikehisupan sehari - hari yang diharapkan dapat meningkatkan kemampuan pemecahan masalah matematis siswa dan memberikan pengalaman belajar yang baru.

\section{KESIMPULAN}

Berdasarkan hasil penelitian di atas dapat disimpulkan bahwa penerapan bahan ajar matematika berbasis Realistic Mathematics Education (RME) menunjukan pengaruh yang baik terhadap kemampuan pemecahan masalah matematis siswa. Terdapat faktor yang mempengaruhi hal tersebut diantaranya

1. di dalam bahan ajar terdapat permasalah konstektual,

2. siswa lebih termotivasi karena berkaitan dengan kehidupan sehari-hari.

\section{SARAN}

Diharapkan terdapat penelitian lanjutan terkait dengan penerapan bahan ajar berbasis Realistic Mathematics Education (RME) ini.

\section{DAFTAR PUSTAKA}

Islamiah, N., Purwaningsih, W. E., Akbar, P., \& Bernard, M. 2018. Analisis Hubungan Kemampuan Pemecahan Masalah Matematis dan Self Confidence Siswa SMP. Journal on Education, 1(1), 47-57.

Imswatama, A., \& Lukman, H. S. 2018. Penerapan Bahan Ajar Matematika Berbasis Etnomatematika terhadap Kemampuan Pemecahan Masalah Matematis Siswa. Prosiding SENAMKU, 1, 92-100.

Afriansyah, E. A. 2016. Makna Realistic dalam RME dan PMRI. Lemma, 2(2).

Kusumawardani, Dyah Retno, Wardono Wardono, and Kartono Kartono. 2018. Pentingnya Penalaran Matematika dalam Meningkatkan Kemampuan Literasi Matematika. PRISMA, Prosiding Seminar Nasional Matematika. Vol. 1

National Council of Teachers of Mathematics (NCTM). (2000). Principles and Standards for School Mathematics. Reston, VA: NCTM.

National Council of Teachers of Mathematics (NCTM). (2000). Principles and Standards for School Mathematics. Reston, VA: NCTM.

Ningsih, Seri. 2014. Realistic Mathematics Education: Model Alternatif Pembelajaran Matematika Sekolah. Jurnal Pendidikan Matematika 1.2: 73-94.

Marpaung, Yansen, and Hongki Julie. 2011. PMRI dan PISA: Suatu usaha peningkatan mutu pendidikan matematika di Indonesia. Widya Dharma.

OECD. 2015. PISA 2012 Result: What Students Know and can Do-Student Performance in Mathemathics, Reading and Science (Volume I). PISA: OECD Publishing.

Siagian, Muhammad Daut. 2016. "Kemampuan koneksi matematik dalam pembelajaran matematika." MES: Journal of Mathematics Education and Science 2.1

Ubaidillah, Mochamad Farid, Subanji Subanji, and Cholis Sa'dijah. "Bahan Ajar Berbasis Realistic Mathematic Education (Rme) Materi Operasi Hitung Untuk Siswa Sekolah Dasar." Prosiding Seminar Nasional Mahasiswa Kerjasama Direktorat Jenderal Guru dan Tenaga Kependidikan 
Kemendikbud 2016. 2017. "Pengertian Matematika - Bidang, Logika,

Karakteristik, Manfaat, Para Ahli” www.gurupendidikan.co.id. 21/02/2020. 20/06/2020.

https://www.gurupendidikan.co.id/penger tian- matematika/ 